\title{
NEMO-Bohai 1.0: a high-resolution ocean and sea ice modelling system for the Bohai Sea, China
}

\author{
Yu Yan ${ }^{1,2,3}$, Wei Gu${ }^{2}$, Andrea M. U. Gierisch ${ }^{4}$, Yingjun $\mathrm{Xu}^{2}$, Petteri Uotila ${ }^{3}$ \\ ${ }^{1}$ School of Ocean Sciences, China University of Geosciences, Beijing 100083, China \\ $5{ }^{2}$ Academy of Disaster Reduction and Emergency Management, Faculty of Geographical Science, \\ Beijing Normal University, Beijing 100875, China \\ ${ }^{3}$ Institute for Atmospheric and Earth System Research (INAR), Faculty of Science, University of \\ Helsinki, 00014 Helsinki, Finland \\ ${ }^{4}$ Danish Meteorological Institute, DK-2100 Copenhagen, Denmark \\ Correspondence to: Yu Yan (yuyan@cugb.edu.cn) and Petteri Uotila (petteri.uotila@helsinki.fi)
}

\begin{abstract}
Severe ice condition in the Bohai Sea could cause serious harm to maritime traffic, offshore oil exploitation, aquaculture, and other economic activities in the surrounding regions. In addition to providing sea ice forecasts for disaster prevention and risk mitigation, sea ice numerical models could help explain the sea ice variability within the context of climate change in marine ecosystems, such as that of spotted seals, which are the only ice-dependent sea animal that breeds in Chinese waters. Here, we developed NEMO-Bohai, an ocean-ice coupled model based on the Nucleus for European Modelling of the Ocean (NEMO) model version 4.0 and Sea Ice modelling Integrated Initiative $\left(\mathrm{SI}^{3}\right)(\mathrm{NEMO} .0-$ $\mathrm{SI}^{3}$ ) for the Bohai Sea. This study will present the scientific design and technical choices of the parameterizations for the NEMO-Bohai model. The model was calibrated and evaluated with in situ and satellite observations of ocean and sea ice. The model simulations agree with the observations with respect to sea surface height (SSH), temperature (SST), and salinity (SSS). The seasonal variation of the sea ice area is well simulated by the model compared to the satellite remote sensing data for the period of 1996-2017, and there are similar overall statistics in the occurrence dates of annual maximum sea ice area. The simulated sea ice thickness and volume are in general agreement with the observations with slight over-estimations. NEMO-Bohai is able to simulate seasonal sea ice evolution and long-term interannual variations. Hence, Nemo-Bohai is intended to be a useful tool for long-term ocean and ice simulations as well as the ocean and climate change studies.
\end{abstract}




\section{Introduction}

The Bohai Sea is the southernmost seasonal frozen sea in the Northern Hemisphere (Yan et al., 2017). The sea ice season is generally from December to March, and the sea ice in the Bohai Sea exhibits significant interannual variability, which could cover half of sea area during severe winters (Su and Wang, 2012). With four of China's top ten ports (Tianjin, Tangshan, Dalian, Yingkou), the Bohai Sea is an important economic zone in China (Fu et al., 2017). Under severe sea ice conditions, such as during the 2009/2010 winter, 296 ports in this region were frozen. In particular, the $42 \mathrm{~km}$ artificial waterway of Huanghua Port was covered by sea ice; thus, the maritime traffic was severely restricted, and 7157 fishing vessels were damaged (Gu et al., 2013). Two hundred seven thousand hectares offshore aquatic farms were covered by sea ice, and the aquaculture industry losses reached $\sim 6$ billion yuan ( $\sim 878$ million U.S. dollars) (Zhang et al., 2013). In addition, ice floes drift on the Bohai Sea surface under the drive of winds, lights, and lighthouses) or ships, convergent ice motion seriously threatens marine transportation and oil and gas exploration (Leppäranta, 2011; Li et al., 2011; Yan et al., 2019). Thus, sea ice monitoring and forecasting is essential for assessing sea-ice-hazard risk and preventing ice disasters.

In addition, spotted seals (Phoca largha), which are distributed in the Northwest Pacific Ocean where Liaodong Bay of the Bohai Sea represents the southernmost geographic breeding concentration of this species, are listed as least concern species by the International Union for the Conservation of Nature Red List of Threatened Species and as a Grade II state protection species by China's Wild Animal Protection Law (1988). At the end of October each year, the seals traveled from the Yellow Sea to Liaodong Bay. However, the population of the spotted seal has experienced several drastic declines from $\sim 2300$ to $\sim 1000$ individuals over the past three decades due to hunting and environmental pollution (Yan et al., 2018; Yang et al., 2017). They den in coastal areas and on offshore drifting ice. When the sea ice melts, they gradually leave Liaodong Bay and embark on a long journey back to the Pacific Ocean. Therefore, the realization of long-term changes in Bohai Sea ice is crucial to learn how sea ice changes impact spotted seals.

Most research have focused on the polar region, however, sea ice in mid-high latitude is also sensitive to climate change (Bai et al., 2011; Gong et al., 2007; Yan et al., 2017). Knowledge of regional sea ice variability is important to study how climate change will affect regional basins. The traditional 
view on the Bohai Sea ice is concentrated on extracting sea ice data from satellite imagery (Karvonen et al., 2017; Shi and Wang, 2012; Su et al., 2019). As the use of remote sensing data to retrieve sea ice data an effective tool to understand the sea ice continuous process from freezing to thawing (Hordoir et al., 2019; Pemberton et al., 2017).

Sea ice models can reasonably simulate sea ice conditions, which can largely supplement remote Earth observations. To our knowledge, there are only very few studies on developing regional coupled ocean-ice models for the Bohai Sea, and most of them have focused on short-duration simulations, such as one week and one-year case studies. Wang et al. (1984) reported the first sea ice dynamicthermodynamic model for the Bohai Sea, which simulated the sea ice freezing-melting cycle at a resolution of $20 \mathrm{~km} \times 20 \mathrm{~km}$ driven by monthly climatic forcing. Wu (1991) and Wu et al. (1997) tried to simulate sea ice evolution based on a dynamic-thermodynamic model with consideration of the ice thickness distribution function consisting of three types (level ice, drift ice and open water). Bai and Wu (1998) combined the sea ice dynamic-thermodynamic model, atmospheric boundary layer model, and tide model at a resolution of $8.64 \mathrm{~km} \times 11.11 \mathrm{~km}$. The model was initialized with sea ice data from NOAA and driven by weather forecast data from the Japan Meteorological Agency for each 4-day period between 1990 and 1996. Liu et al. (2003) applied a high-resolution atmosphere model (T213, $0.5625^{\circ} \times 0.5625^{\circ}$ ) to reproduce sea ice conditions in 2002 by a sea ice model initialized by high resolution satellite data from HY-1 and MODIS (250 m). Su et al. (2004) coupled Princeton Ocean Model (POM) and viscous-plastic dynamic-thermodynamic sea ice model, and simulated the winters of 1998 and 2000. Tang et al. (2010) coupled POM with sea ice model considering the thickness distribution function, which was driven by MM5 atmospheric forcing provided by the NMEFC, to simulate the sea ice freezingmelting process in 2003. Zhang and Zhang (2013) used finite-volume, primitive equation community ocean model to simulate sea ice in 2003. To the best of our knowledge, there is no sea ice prediction system for the Bohai Sea for a long enough time to reproduce interannual or interdecadal variability.

The Nucleus for European Modelling of the Ocean (NEMO) is a state-of-the-art numerical modeling framework designed for research activities and forecasting services in ocean and climate sciences (Madec et al., 2016). The NEMO code, including its sea ice component, enables the investigation of ocean-ice dynamics/thermodynamics and their interactions with the atmosphere. NEMO offers a wide range of 
applications from short-term forecasts and climate projections (Drouard and Cassou, 2019; ObermannHellhund et al., 2018; Uotila et al., 2017; Voldoire et al., 2013) to process studies (Courtois et al., 2017; Declerck et al., 2016; Feucher et al., 2019). While global models offer a poor representation of regional ocean processes, regional models have been developed based on the framework of NEMO in recent years, e.g., models for the Atlantic marginal basins (Graham et al., 2018; O'Dea et al., 2017), the Baltic and North seas (Hordoir et al., 2019; Pemberton et al., 2017), the Northwestern Mediterranean Sea (Declerck et al., 2016), the South Indian Ocean (Schwarzkopf et al., 2019), the South China Sea (Thompson et al., 2019), and the Black Sea (Gunduz et al., 2020). However, a regional model for the Bohai Sea based on NEMO has not yet been developed, until now.

Clearly, a coupled ocean-ice model could help improve our understanding of sea ice processes in the Bohai Sea, which is crucial for sea ice disaster prevention, spotted seal habitat studies, and regional climate change studies. The aim of the paper is to report the development of NEMO-Bohai and assess its performance. The paper is organized as follows: Sec. 2 introduces the model and observation dataset. Model comparison and validation is carried out in Sec. 3. The analysis of sea ice variation based on the 22-year hindcast simulations of NEMO-Bohai is presented in Sec. 4. Discussion and a short summary are provided in Sec. 5 .

\section{Model setup: NEMO-Bohai}

NEMO-Bohai is localized to the Bohai Sea based on the NEMO ocean engine (Madec et al., 2016).

105 Here, we apply the NEMO 4.0 beta and Sea Ice Integrated Initiative $\left(\mathrm{SI}^{3}\right)$ model in a regional configuration covering the Bohai Sea. The regional configuration, NEMO-Bohai, is nested into the global configuration (ORCA025) using one-way lateral boundary conditions with the flow relaxation scheme algorithm (Engedahl, 1995). The sea surface heights (SSHs), temperatures, salinity levels, and velocities are relaxed to outer-model values over a 1-point zone at the unstructured open boundary of the model domain. In addition, NEMO 4.0 and the use of the XIOS server is a key element in a more user-friendly version of NEMO-Bohai. 


\subsection{Global ocean-ice model ORCA025}

A global $1 / 4^{\circ}$ ocean-ice model (ORCA025) maintained by the DRAKKAR group is presented. The fundamental conservation laws of mass, momentum and energy in NEMO are resolved in a curvilinear coordinate system with discretization on a staggered grid (Arakawa $\mathrm{C}$ grid). The horizontal grid has a $0.25^{\circ}$ resolution at the equator, leading to $1442 \times 1207$ grid points horizontally, and there are 75 vertical levels in the model configuration with a grid spacing between 1 200 $\mathrm{m}$ from the top to the bottom. In our simulation, forcing fields are provided from the Japanese 55-year Reanalysis (Harada et al., 2016; Kobayashi et al., 2015), covering the 55 years from 1958 with $0.5^{\circ} \times 0.5^{\circ}$ spatial resolution. The variables include of wind speed ( $\mathrm{u} / \mathrm{v}$ component), 2-m air temperature, surface downwelling shortwave/longwave radiation, near-surface specific humidity, rainfall flux, snowfall flux, and sea-level pressure at 3-hourly intervals. The generic bulk formula (Large and Yeager, 2009) is used for the surface boundary condition (SBC) and the frequency of the SBC and sea ice model calls every time step (ca. every $15 \mathrm{~min}$ ). A monthly climatological runoff flux with Antarctic ice shelves and iceberg meltwater flux (Dai et al., 2009; Depoorter et al., 2013) is used. Penetrative solar radiation is applied through the RGB light penetration formulation to split visible light to Red-Green-Blue wavebands. To limit the atmospheric forcing biases from propagating into the upper ocean and avoid salinity and temperature drift, which impacts the overturning circulation, the sea surface temperature (SST) and salinity (SSS) are restored monthly based on the World Ocean Atlas-2013 (Locarnini et al., 2013; Zweng et al., 2013).

The split-explicit free surface formulation is implemented, and no-slip lateral boundary conditions are chosen. The linear top/bottom friction parameterization, which assumes that the top/bottom friction is proportional to the interior velocity, is applied in the simulation. The Laplacian operator is used in the iso-level direction in the lateral diffusion scheme for tracers, and the eddy coefficient is set to a constant. Tracer advection is achieved using a flux-corrected transport (FCT) scheme (Zalesak, 1979). The turbulent kinetic energy (TKE) closure scheme (Blanke and Delecluse, 1993) is used for vertical physics setting. The simulation is spun up in January 1987 with rest state and ended in 2017. The time step is set to $900 \mathrm{~s}$. The ORCA025 configuration is performed using 240 CPU cores on a Cray XC40 system on the Sisu supercomputer and requires $\sim 6000 \mathrm{CPU}$ hours per simulated year. The model output frequency is set to every 5 days for the period from 1987 to 1994 for the test run and increases to every day for the 
of 1995-2017. For the regional model, NEMO-Bohai, the interface between open boundaries is forced by barotropic and baroclinic modes.

\subsection{NEMO-Bohai: The ocean model}

The NEMO-Bohai domain consists of one central zone and three bays (see Fig. 1). The area covers

$117^{\circ}-122^{\circ} \mathrm{E}$ and $37^{\circ}-41^{\circ} \mathrm{N}$. The horizontal resolution is $0.025^{\circ}$ in orthogonal curvilinear coordinates, which is equivalent to a resolution of approximately $2 \mathrm{~km}(204 \times 244=49776$ grid points $)$. The bathymetry is interpolating into the target grids according to the ETOPO1 1 arc-minute dataset. We further manually remove the isolated land cells with number less than 4 . The vertical discretization scheme adopts $z *$ formulation. There are 10 vertical levels, and the top layer is set to $1 \mathrm{~m}$. The partial step is applied to the bottom topography. The time step of the ocean model is set to $90 \mathrm{~s}$, while it calls the sea ice model every three time steps. The split-explicit time stepping method $(f \not \hat{e} \mid \cdot a>$ " $i$ êfi> $\left.\left.\ddot{y} \_f i<f l\right\}_{\beth}\right)$ is used to compute barotropic/baroclinic mode and their interactions.

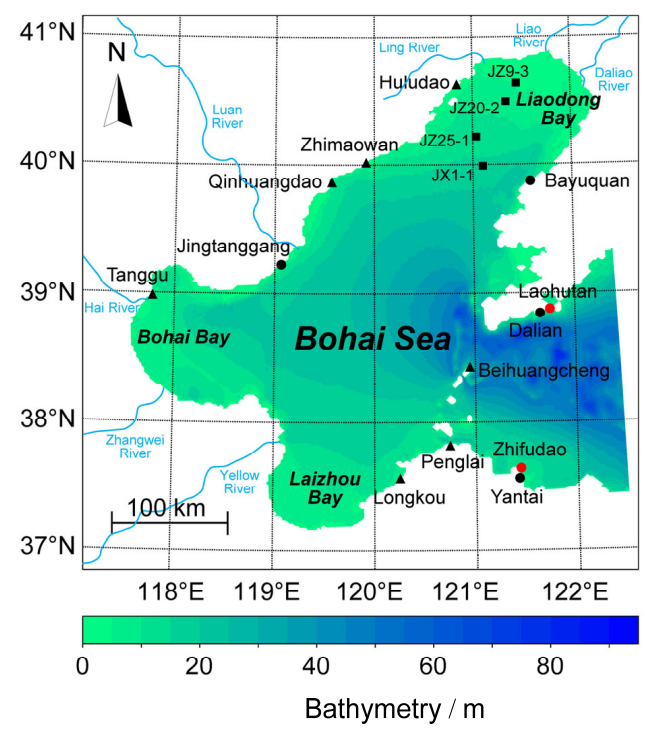

Figure 1: The location and bathymetry of the Bohai Sea. The black dots denote the coastal tide gauge stations.

The red dots indicate the sea surface temperature observation stations. The black squares denote the oil platforms where the sea ice thickness was conducted. The black triangles indicate the sea surface salinity observation stations. The straight line in the east denotes open boundary for the regional ocean model.

The initial conditions of the numerical simulation in the Bohai Sea for July 1, 1995, including SST and SSS, are obtained by interpolating the temperature and salinity fields from the global ocean 

lateral ocean boundary conditions, tidal forcing, atmospheric forcing, and river runoff during the study period. Two kinds of boundary condition are used for the setting of lateral open ocean boundary. Flow relaxation scheme is applied to baroclinic velocities and tracers (Engedahl, 1995), while Flather boundary condition (Flather, 1976) is used for barotropic dynamics, such as SSH and barotropic velocities $\left(\mathrm{fl}^{-} \mid{ }^{1}\right.$ $-^{-} \mid$). NEMO-Bohai has one open boundary located $100 \mathrm{~km}$ away from the Bohai Strait, and we set the relaxation zone width to 1 ( $\not \mathfrak{Q} \hat{e ̂}<£ \S \dagger £ \mid$ fic $\ddot{y} \sim)$. The lateral open ocean boundary conditions for 1995 to 2017 are also taken from a series of global ocean simulations with the ORCA025 hindcast. The Oregon State University Tidal Inversion Model is used for the barotropic mode (Egbert and Erofeeva, 2002), which includes 11 tidal harmonics (M2, S2, N2, K2, K1, O1, P1, Q1, M4, MS4, MN4). We choose TPXO9.1 global tide model, which is the latest version with a $0.25^{\circ} \times 0.25^{\circ}$ resolution.
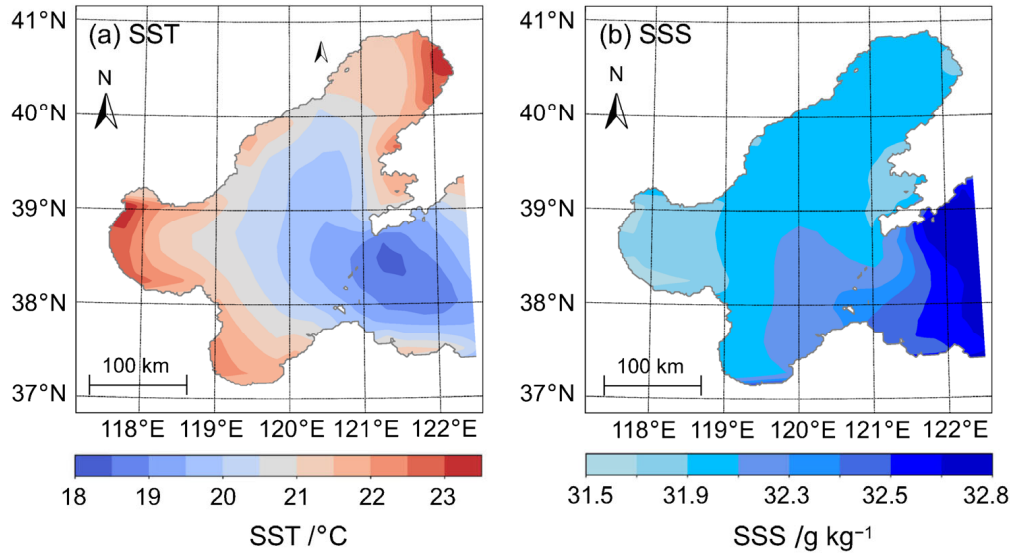

Figure 2: Examples of (a) initial sea surface temperature (SST) field and (b) initial sea surface salinity (SSS) field interpolated from the global ORCA025 model simulation on July 1, 1995.

The NEMO-Bohai atmospheric forcing is derived from the ERA5 dataset, which is the ECMWF's latest reanalysis product covering the period from 1979 to the present and has replaced the widely used ERA-Interim dataset. The data cover the Earth with a horizontal spatial resolution of $30 \mathrm{~km}$ and represent the atmosphere using 137 levels from the surface up to a height equaling $0.01 \mathrm{hPa}$. The forcing files consist of 1 hourly instantaneous fields of the $2 \mathrm{~m}$ air temperature, $10 \mathrm{~m}$ wind speed, downward short/long wave radiation, sea-level pressure, specific humidity, and precipitation. The equivalent inverse barometer SSH is calculated from the atmospheric pressure $(f \mathfrak{a} \hat{e} y "<\hat{e} \mid \cdot a \quad \ddot{y} \quad \beth f i<f l\} \beth)$ with the 
referenced pressure of $101,000 \mathrm{~N} \mathrm{~m}^{-2}$. In addition, the river runoff, which provides a significant volume of freshwater to the Bohai Sea and influences stratification, circulation, and primary productivity, is considered in the model. The daily runoff volume data for the rivers flowing into the Bohai Sea, such as the Yellow River, Liao River, and Hai River, are acquired from JRA-55 from 1995 to 2018. The runoff forcing is considered as fresh water with salinity of $0 \mathrm{~g} \cdot \mathrm{kg}^{-1}$ and same temperature as the ocean surface.

The bottom roughness impacts the dynamics of the tide, ocean circulation and storm surges in the Bohai Sea. A constant bottom roughness ( $\left\langle\right.$ aê $q^{`}$ ) is used to calculate the drag coefficient for all bottom grids. To better reflect changes in the tide and circulation, we tune the bottom roughness accordingly.

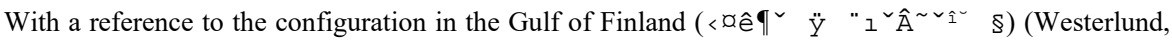
190 2019), we set <uê $\Upsilon^{\smile}$ to $5.0 \times 10^{-1}, 5.0 \times 10^{-2}, 5.0 \times 10^{-3}, 5.0 \times 10^{-4}, 5.0 \times 10^{-5}$, and $5.0 \times 10^{-8}$ while keeping all the other variables consistent. Results show that reducing the bottom friction can increase the phase difference and amplitude of the tide. In NEMO-Bohai, the smaller the roughness value is, the more accurate the tide is. However, it also needs to be combined with the actual situation at the bottom of the Bohai Sea. With reference to (Zhang and Zhang, 2013), the bottom roughness had a magnitude of $1 \times 10^{-}$

${ }^{3} \mathrm{~m}$. Therefore, the bottom roughness in NEMO-Bohai is determined to be $5.0 \times 10^{-3} \mathrm{~m}$. For the bottom drag coefficient, we set $\left\langle\right.$ Q êe $\left.\right|^{\vee}$ to default value after a set of experiments similar to the abovementioned. The TKE closure scheme is used for vertical mixing (Blanke and Delecluse, 1993) with the default values of vertical eddy viscosity and diffusivity coefficients, and the FCT scheme (Zalesak, 1979) is responsible for the tracer advection. Some key parameters of the ocean part of NEMO-Bohai are listed in Table 1.

Table 1: Key physical parameters in the ocean namelist (namelist_oce) in NEMO-Bohai.

\begin{tabular}{|c|c|c|c|c|c|}
\hline Parameter & Namelist & Setting & Parameter & Namelist & Setting \\
\hline Time step & $<\mathrm{dê}<\mid \mathrm{fi}$ & $90 \mathrm{~s}$ & Activate tides & $f$ âfí $\mid\}$ & true \\
\hline $\begin{array}{l}\text { Frequency of surface } \\
\text { module call }\end{array}$ & agê $\sim z\{$ & 3 & $\begin{array}{l}\text { Hydrostatic pressure } \\
\text { gradient option }\end{array}$ & $f$ œêc " i $\hat{e}>\{$ ' & true \\
\hline Relaxation zone width & adê< $<£ \S \dagger £ \mid f i c$ & 1 & Ocean equation of seawater & $f$ ấ $\}$ '>" & true \\
\hline Bottom roughness & $<$ âी & $5.0 \times 10^{-3} \mathrm{~m}$ & Penetrative solar radiation & $f 0 \hat{e} \ll><\hat{e}<i z$ & true \\
\hline Top drag coefficient & $<$ QQ̂́Z| & $1.0 \times 10^{-3}$ & Advection scheme for tracer & $f$ aêfi $<y y \mid-\hat{e} \sim\{f i$ & true \\
\hline Bottom drag coefficient & $\left\langle\right.$ oêz| $\left.\right|^{2}$ & $1.0 \times 10^{-3}$ & $\begin{array}{l}\text { Standard operator of lateral } \\
\text { diffusion scheme for tracers }\end{array}$ & $f$ Qêfi $\langle y f \mid \sim \hat{e} E\rangle$ ' & true \\
\hline $\begin{array}{l}\text { Lateral momentum } \\
\text { boundary condition }\end{array}$ & $\langle\mathrm{Qê}\rangle \dot{\xi} f \mathrm{yfi}$ & 0 & $\begin{array}{l}\text { Laplacian operator of lateral } \\
\text { diffusion on momentum }\end{array}$ & $f \not \hat{e}\left|\cdot a_{f}\right| \sim \hat{e} f Y^{\prime \prime}$ & true \\
\hline Vertical eddy viscosity & $<$ ây-§ & $1.2 \times 10^{-4} \mathrm{~m}^{2} \cdot \mathrm{s}^{-1}$ & Surface pressure gradient & $f$ âe $\mid \cdot a>{ }^{\prime} i$ êfi> & true \\
\hline Vertical eddy diffusivity & $<$ dêy-fi ${ }^{2}$ & $1.2 \times 10^{-5} \mathrm{~m}^{2} \cdot \mathrm{s}^{-1}$ & Vertical physics & $f$ aê $\mid$ fił $\}$ & true \\
\hline Ocean initialization & $f$ âefi> $\mid \hat{e ̂ E}_{£} \alpha_{£ i}$ & true & Top/bottom drag coefficient & $f$ âf $f^{\prime}$ i $\left.f y \cdot\right\}<$ & true \\
\hline
\end{tabular}




\subsection{NEMO-Bohai: The sea ice model}

$\mathrm{SI}^{3}$ is recommended by the Sea Ice Working Group to reduce duplication and better use development resources (Aksenov et al., 2019). $\mathrm{SI}^{3}$ merges the capabilities of three sea ice models previously used in NEMO (CICE, GELATO and LIM). $\mathrm{SI}^{3}$ is a horizontal dynamic and vertical thermodynamic sea ice

model. The thermodynamics and dynamics are separated and rely upon different frameworks and sets of hypotheses: thermodynamics use the ice thickness distribution and the mushy-layer frameworks, whereas dynamics assume continuum mechanics, e.g., Leppäranta (2011). Thermodynamics and dynamics interact in two ways: first, advection impacts the ice state variables; second, the horizontal momentum equation depends on, among other things, the ice state. The modified elastic-viscous-plastic rheology is used for sea ice dynamics (Bouillon et al., 2013; Kimmritz et al., 2017). Bohai Sea ice is relatively thin and has low salinity, which is different with polar ice (Gu et al., 2013). Therefore, the parameters in NEMO-Bohai is required to be modified accordingly.

In NEMO-Bohai, we selected and adjusted a series of sea ice model parameters. We increase the number of ice categories $(/ " f)$ and the number of ice layers $\left(\alpha_{f y} \cdot \hat{e} £\right)$ since Massonnet et al. (2019) suggested that increasing the resolution of the ice thickness distribution results in small but nonnegligible variations in the ice extent and volume. The ice thickness is discretized into ten categories $(0.0$, $0.0476,0.0976,0.150,0.205,0.263,0.324,0.388,0.455,0.526,0.601 \mathrm{~m})$, and the thermodynamic calculations used five ice layers ( $\left.a_{f y} \cdot \hat{e ̂ f}_{£} \ddot{Y} "\right)$. The minimum ice thickness used in remapping is set

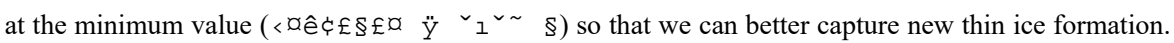

Thickness of new ice formed in open waters $(<\mathrm{Q} \hat{e} \xi £ \mathfrak{Q}\} \dagger)$ is set to $0.02 \mathrm{~m}$ as the value must be larger than $\langle a \hat{e} \xi \mathfrak{Q}\}+£\{\}$. According to the test run of NEMO-Bohai, the sea ice thickness is generally overestimated. Compared to the referenced value of $2.0 \mathrm{~m}$, we reset the average ice thickness ( $<$ ấ§£§\} $\mathrm{Y}^{\mathrm{d}}$ ) as $0.20 \mathrm{~m}$ according to the observations (Li et al., 2004; Yuan et al., 2012).

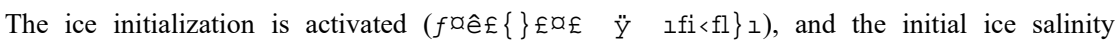

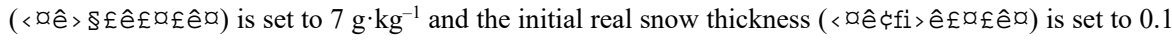
$\mathrm{m}$ according to in situ observations (Bai and Wu, 1998; Gu et al., 2014). For the snow and ice albedos, we set them to lower values compared to the referenced ones based on the in situ observations (Zheng et al., 2017). The ice strength parameter ( $<$ âe " > fiy $<$ ) is defined as $2.75 \times 10^{4} \mathrm{~N} \mathrm{~m}^{-2}$ based on previous in situ studies (Li et al., 2011). A ridging scheme is considered in $\mathrm{SI}^{3}$, thus he parameter < âe $\dot{\xi}>$ fiy <, which 
adjusts the maximum thickness of ridged ice, is reduced from $100.0 \mathrm{~m}$ to $10.0 \mathrm{~m}$ following the NEMONORDIC 1.0 configuration (Pemberton et al., 2017) to reflect the general thinner Bohai Sea ice. In

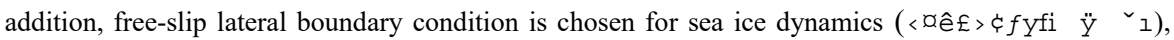
which is synchronized with the ocean model, and a landfast parameterization is set

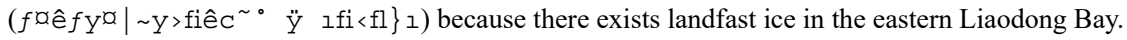

In this section, we analyze how well NEMO-Bohai reproduces ocean properties (SSH, SST and SSS) and sea ice properties (area, thickness and volume). To evaluate model's performance, we compare our model results to in situ and satellite observations from 1996 to 2017.

\subsection{Observational data}

To evaluate the SSH, the modeled tide amplitude and phase were compared to the tide tables with hourly intervals of Yantai $\left(37.550^{\circ} \mathrm{N}, 121.383^{\circ} \mathrm{E}\right)$, Dalian $\left(38.867^{\circ} \mathrm{N}, 121.683^{\circ} \mathrm{E}\right)$, and Jingtanggang $\left(39.217^{\circ} \mathrm{N}, 119.017^{\circ} \mathrm{E}\right)$ from National Marine Data and Information Service during the period of October 1 to 31, 2012. In addition, we use in situ observed data from the National Marine Environmental Monitoring Center. The sampling station is at Bayuquan $\left(39.804^{\circ} \mathrm{N}, 121.456^{\circ} \mathrm{E}\right)$, and the sampling period is from January 1 to 31,2013 . For the SST evaluation, we use data from the National Marine Science Data Center. The coastal stations are located at Laohutan in Dalian $\left(38.90^{\circ} \mathrm{N}, 121.70^{\circ} \mathrm{E}\right)$ and Zhifudao in Yantai $\left(37.60^{\circ} \mathrm{N}, 121.40^{\circ} \mathrm{E}\right)$. The observed records cover the periods of 2000-2001, 2010 (July-December), and 2011-2015. For the sea surface salinity, the in situ observed data for 8 ocean stations (Wentuozi, Huludao, Zhimaowan, Qinhuangdao, Tanggu, Longkou, Penglai, Beihuangcheng) in the Bohai Sea is from Yuan et al. (2015). Specifically, the observation period in Huludao, Zhimaowan, Qinhuangdao, Tanggu, Longkou, and Beihuangcheng is from 1960 to 2013, while the period in Wentuozi and Penglai is 1987-2001 and 2012-2013, respectively.

The sea ice model is evaluated by a series of observational datasets. A satellite-derived dataset covered the winters from 1988 to 2017 was retrieved. Sea ice area is extracting based on the zonal threshold method for Advanced Very High Resolution Radiometer (AVHRR) during 1988-2000, while an object-based feature extraction method is applied for Moderate Resolution Imaging Spectroradiometer 
(MODIS) from 2001 to 2017, and the detailed description can be seen from Yan et al. (2017). The shapefiles derived by the abovementioned methods are further modified by visual interpretation with the aim to build a more accurate sea ice area dataset. For the sea ice thickness evaluation, we use the in situ observations from four offshore oil platforms (see Fig. 1) during 2012-2013 (Zeng et al., 2016; Karvonen et al., 2017). The data were collected on January 2, 6, 9, 16, 26, February 2, 9, 12, 16.

\subsection{Ocean}

\subsubsection{Sea surface height}

Reliable precision of tidal model is pre-required for subsequent simulations in NEMO-Bohai. In intervals were compared with the simulated results. As presented in Fig. 3, model reproduced well the semidiurnal M2 tidal cycle with exact phase and amplitude at all four stations. The mean absolute errors for the four stations are $0.14,0.18,0.17$ and $0.20 \mathrm{~m}$, respectively. The reasonable accuracy of the hydrodynamic model can assure the simulations of sea ice process of growth and melting in the following session.
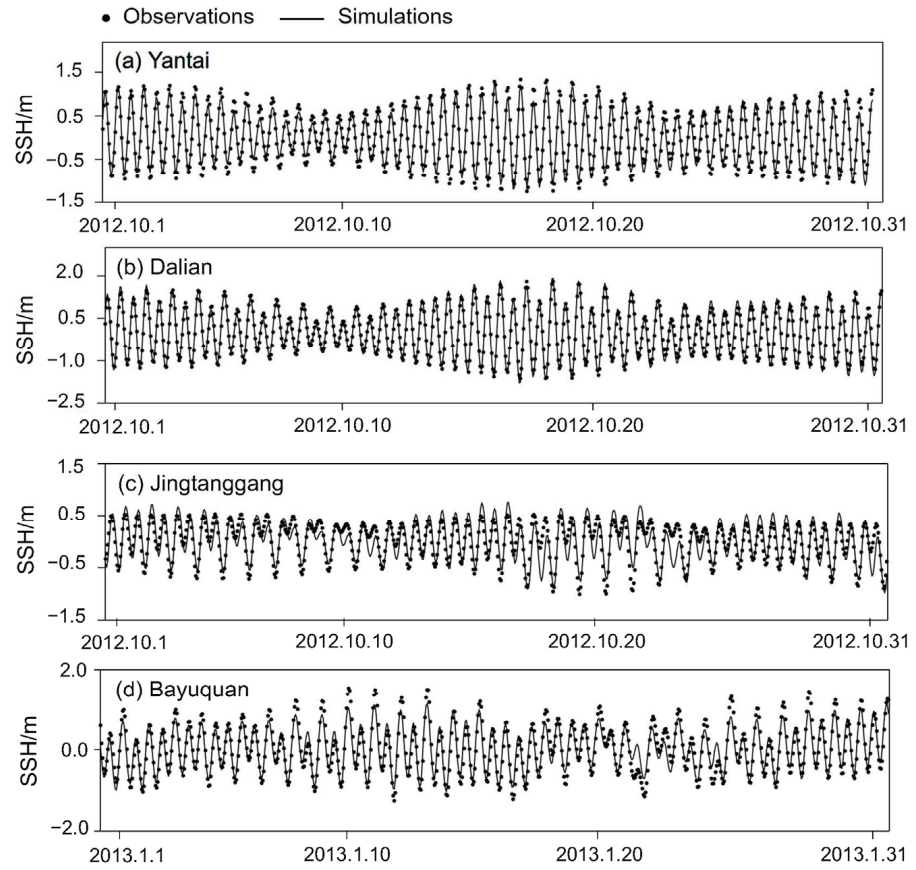

Figure 3: Comparison of sea surface height (SSH) between the observations and NEMO-Bohai simulations at (a) Yantai, (b) Dalian, (c) Jingtanggang, and (d) Bayuquan stations in the Bohai Sea. 


\subsubsection{Sea surface temperature and salinity}

As shown in Fig. 4, the modeled SST followed well the seasonal cycle and the mean absolute error (MAE) was typically less than $1{ }^{\circ} \mathrm{C}$ at Laohutan and Zhifudao stations during the observed period. The modeled variations of SST are smoother than the observations, particularly failed to capture the high fluctuations of daily variations in summer/autumn at both stations. It is also noticeable that the simulated SST at Zhifudao are generally colder in winter and warmer in summer than the observations.
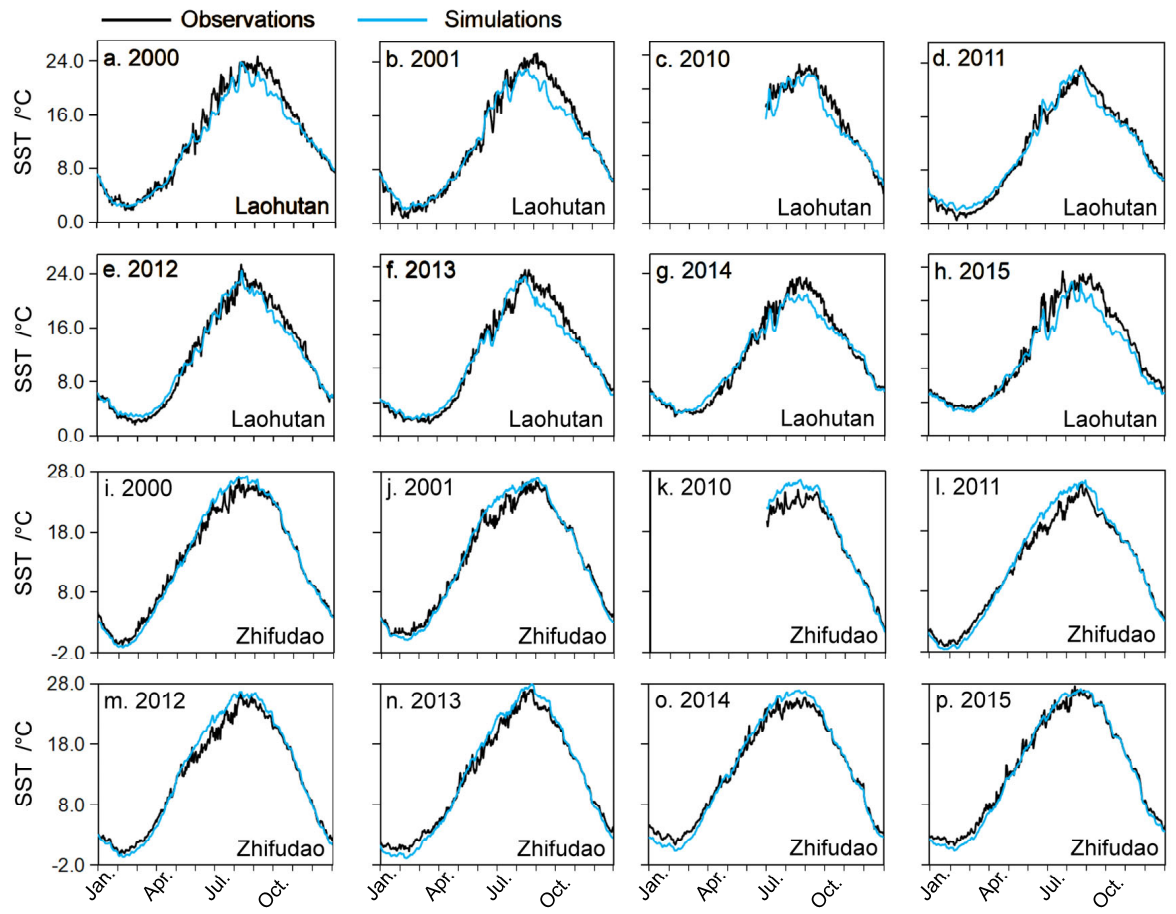

Figure 4: The simulated sea surface temperature (SST) compared with in situ observations at Laohutan, Dalian (a-h) and Zhifudao, Yantai (i-p) for the period of 2000-2001 and 2010-2015 respectively.

Table 3 displays the comparisons of multi-year average sea surface salinities at 8 ocean stations in the Bohai Sea between simulations from NEMO-Bohai and observations reported by Yuan et al. (2015).

Generally speaking, NEMO-Bohai is able to capture the main variations of the sea surface salinity in the

Bohai Sea. Values at six ocean stations agree with observations with the relative deviation less than 5\%, while the modeled values at Huludao and Tanggu are less salty than observed. This demonstrates that the model faces larger challenges in the low salinity areas. As we know, the freshwater inputs from rivers would lead to lower salinity in the coastal areas. In the model, the river salinity in NEMO-Bohai is 

runoff and shallow water depth (generally $<3 \mathrm{~m}$ ) also need to be taken into considerations.

Table 3: Comparison of multi-year average sea surface salinity between the observations and simulations.

\begin{tabular}{cccccc}
\hline Station & $\begin{array}{c}\text { longitude } \\
\left({ }^{\circ}\right)\end{array}$ & $\begin{array}{c}\text { Latitude } \\
\left({ }^{\circ}\right)\end{array}$ & $\begin{array}{c}\text { Observations } \\
\left(\mathbf{g ~ k g}^{-1}\right)\end{array}$ & $\begin{array}{c}\text { Simulations } \\
\left(\mathbf{g ~ k g}^{*} \mathbf{)}\right.\end{array}$ & $\begin{array}{c}\text { Relative } \\
\text { deviation }\end{array}$ \\
\hline Wentuozi & 121.41 & 39.72 & 30.5 & 30.1 & $-1.3 \%$ \\
Huludao & 120.81 & 40.56 & 29.6 & 23.2 & $-21.6 \%$ \\
Zhimaowan & 119.92 & 40.02 & 30.8 & 31.0 & $+0.6 \%$ \\
Qinhuangdao & 119.62 & 39.92 & 30.4 & 31.0 & $+0.6 \%$ \\
Tanggu & 117.78 & 38.98 & 29.3 & 25.4 & $-13.3 \%$ \\
Longkou & 120.32 & 37.65 & 28.2 & 28.0 & $-0.7 \%$ \\
Penglai & 120.73 & 37.82 & 30.2 & 30.4 & $+0.6 \%$ \\
Beihuangcheng & 120.92 & 38.40 & 31.5 & 32.8 & $+4.1 \%$ \\
\hline
\end{tabular}

${ }^{*}$ The observed sea surface salinity data is referenced from Yuan et al. (2015).

\subsection{Sea ice}

Sea ice is the focus of our study and is, in this section, directly validated against observations with respect to the area, thickness, volume and their variations.

\subsubsection{Sea ice area}

To evaluate the performance of NEMO-Bohai in simulating the characteristics of sea ice area, series of variables were validated, including the daily sea ice area (DSIA), annual maximum sea ice area (AMSIA), and spatial patterns. Figure 5 shows that the model-estimated DSIA agrees well with the satellite derived observations $(r=0.85, p<0.01)$. In addition to the good agreement of inter-annual variability, the occurrence dates of the AMSIA are quite close to the observed dates from 1996 to 2017 as listed in Table 4. The percentage of the occurrence dates of the AMSIA less than 3 days accounted for $72.7 \%$ and the mean absolute error is 3.5 days. In 2013, the NEMO-Bohai based maximum sea ice area was simulated as occurring on February 9, 2013, which is only 1 day later than reported (North China

305 Sea Branch of State Oceanic Administration, 2013). The date retrieved from MODIS was however determined on January 17 due to missing data on February 8, 2013 as severe cloud covered (Yan et al., 2017). The largest difference happened in the winter of 2010 with 18 days earlier than the observations. Specifically, DSIA exhibited a bi-modal distribution with two remarkable peaks in winter of 2010 . 
https://doi.org/10.5194/gmd-2021-100

Preprint. Discussion started: 16 June 2021

(c) Author(s) 2021. CC BY 4.0 License.

Satellite showed that the AMSIA happened on February 12 followed by the second maximum on January

26, while NEMO-Bohai simulated AMSIA was on January 26 followed by second maximum on February

12. It is worth noting that satellite shows the largest DSIA happened in winter of 2010, while NEMO-

Bohai simulated DSIA reached the maximum in 2011. On the contrary, the modeled occurrence date of the AMSIA was 6 days later than the observed date (February 7) in 2008.

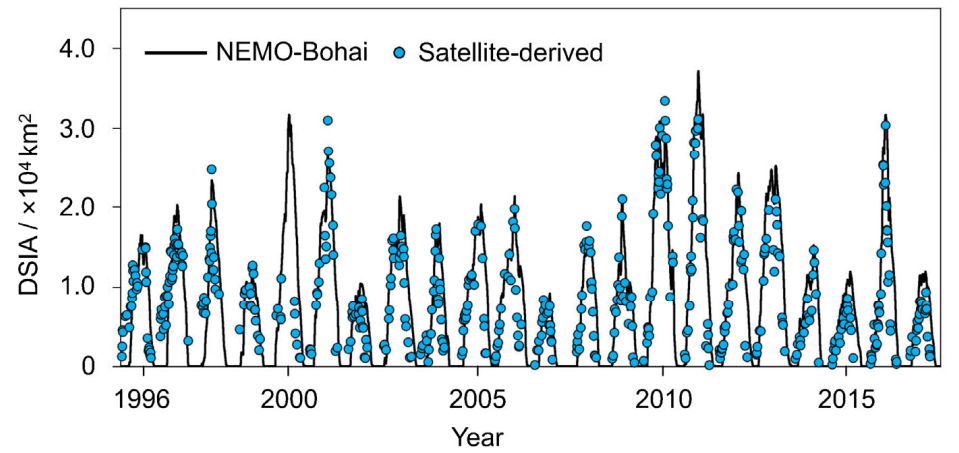

315 Figure 5: Comparison of daily sea ice area (DSIA) between NEMO-Bohai simulations (black line) and satellite-derived data (blue circles) from 1996 to 2017.

Table 4: Comparison of the occurrence dates of the annual maximum sea ice area between the observations and model simulations.

\begin{tabular}{|c|c|c|c|c|c|c|c|}
\hline \multirow[t]{2}{*}{ Year } & \multicolumn{3}{|c|}{$\begin{array}{l}\text { The occurrence dates of } \\
\text { the annual maximum sea ice area }\end{array}$} & \multirow[t]{2}{*}{ Year } & \multicolumn{3}{|c|}{$\begin{array}{l}\text { The occurrence dates of } \\
\text { the annual maximum sea ice area }\end{array}$} \\
\hline & Observed & NEMO-Bohai & Error & & Observed & NEMO-Bohai & Error \\
\hline 1996 & 2.10 & 2.10 & 0 & 2007 & 2.1 & 2.2 & +1 \\
\hline 1997 & 2.3 & 2.3 & 0 & 2008 & 2.7 & 2.13 & +6 \\
\hline 1998 & 1.28 & 1.25 & -3 & 2009 & 1.26 & 1.26 & 0 \\
\hline 1999 & 2.3 & 2.4 & +1 & 2010 & 2.13 & 1.26 & -18 \\
\hline 2000 & 2.8 & 2.3 & -5 & 2011 & 1.30 & 1.31 & +1 \\
\hline 2001 & 2.7 & 2.7 & 0 & 2012 & 2.2 & 2.9 & -7 \\
\hline 2002 & 1.25 & 1.24 & -1 & 2013 & 2.8 & 2.9 & +1 \\
\hline 2003 & 2.2 & 1.30 & -3 & 2014 & 2.12 & 2.11 & -1 \\
\hline 2004 & 2.5 & 2.7 & +2 & 2015 & 2.4 & 2.9 & +5 \\
\hline 2005 & 2.19 & 2.21 & +2 & 2016 & 2.2 & 2.3 & -1 \\
\hline 2006 & 2.8 & 2.9 & +1 & 2017 & 2.12 & 2.11 & -1 \\
\hline
\end{tabular}


The comparison of the spatial distribution of sea ice from NEMO-Bohai simulation and remote sensing inversion during the freeze, severe freeze, and thaw periods in light ice year (2007), normal ice year (2009) and heavy ice year (2010) is shown in Fig. 6. The simulated spatial distributions reflect general characteristics of sea ice evolution in the Bohai Sea except the bias at the ice edge zones. Sea ice is mainly located in Liaodong Bay in light and normal ice years with extension to Bohai Bay and Laizhou cycle of the sea ice but with a relatively slow thawing process.
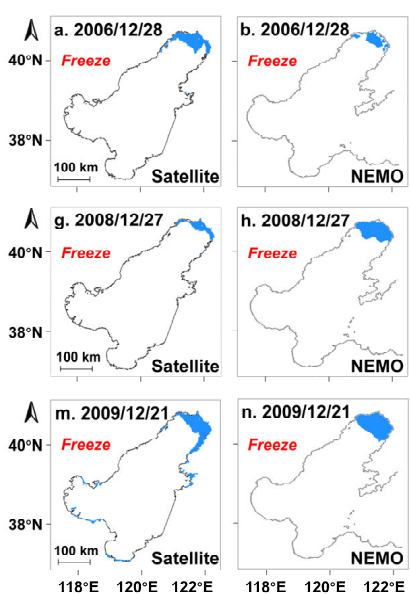
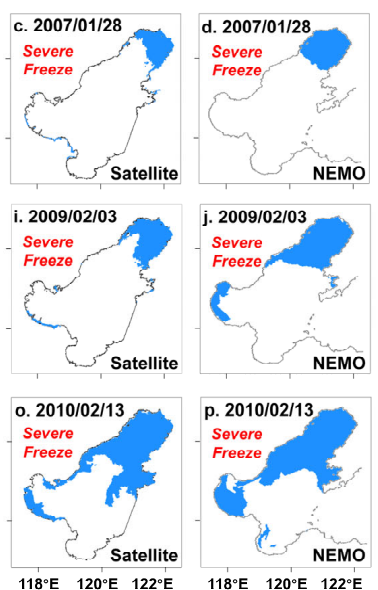
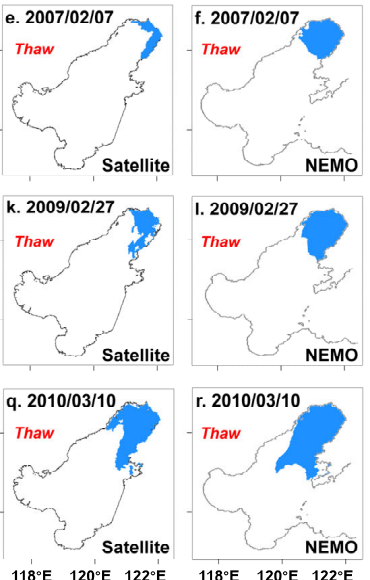

Figure 6: Comparison of spatial distribution of sea ice from NEMO-Bohai simulation and remote sensing inversion in freeze, severe freeze, and thaw periods for light (a-f), normal (g-l) and heavy (m-r) ice years.

\subsubsection{Sea ice thickness and volume}

Fig. 7 shows that the modeled sea ice thickness based on NEMO-Bohai mostly lies in the range of in situ observations with a slight overestimation. The mean relative bias of sea ice thickness between the simulations and observations is $4.6 \mathrm{~cm}(n=37)$. Other studies also revealed that sea ice thickness is overestimated by NEMO in regional studies, such as in the Baltic Sea (Tedesco et al., 2017) and the Canadian Arctic Archipelago (Hu et al., 2018). When comparing ice thickness, the discrepancy of spatial scales makes it difficult to direct compare the modeled average of grids $(\sim 2 \mathrm{~km})$ to exact location in situ measurement as sea ice thickness varies greatly in Bohai Sea especially in the floating ice zone. 


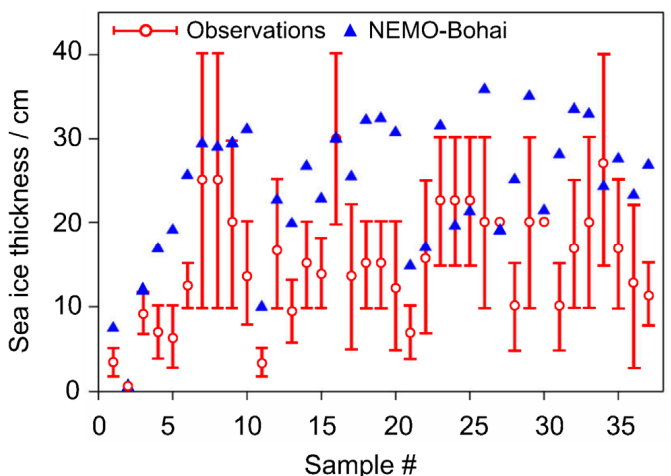

Figure 7: The comparison of sea ice thickness between the simulated and observation data in the Bohai Sea. based on NEMO-Bohai.

Sea ice volume is defined as the total ice over the whole Bohai Sea, which is calculated through sea ice concentration times ice thickness in all grids. As demonstrated in Fig. 8, modeled daily sea ice volume is in reasonable agreement with satellite-derived data between 1996 and 2017. The modeled sea ice volume is higher than the observed with mean relative bias of $15.1 \times 10^{8} \mathrm{~m}^{3}\left(\mathrm{RMSE}=20.3 \times 10^{8} \mathrm{~m}^{3}\right)$. The correlation coefficient between simulations and satellite-derived data is quite high $(r=0.80, p<0.01$, $n=432$ ), indicating reasonable agreement at daily sea ice volume variations. In 2010, NEMO-Bohai simulations reproduced the range of $0.1 \sim 73.0 \times 10^{8} \mathrm{~m}^{3}$, which agrees with the range of $4.4 \sim 63.0 \times 10^{8} \mathrm{~m}^{3}$ reported by Liu et al. (2013) based on AVHRR satellite images. It is noticeable that modeled sea ice volume change is slightly later than the observed by satellite during early freezing period, which is similar to the later phase indicated by the aforementioned comparison of sea ice area.

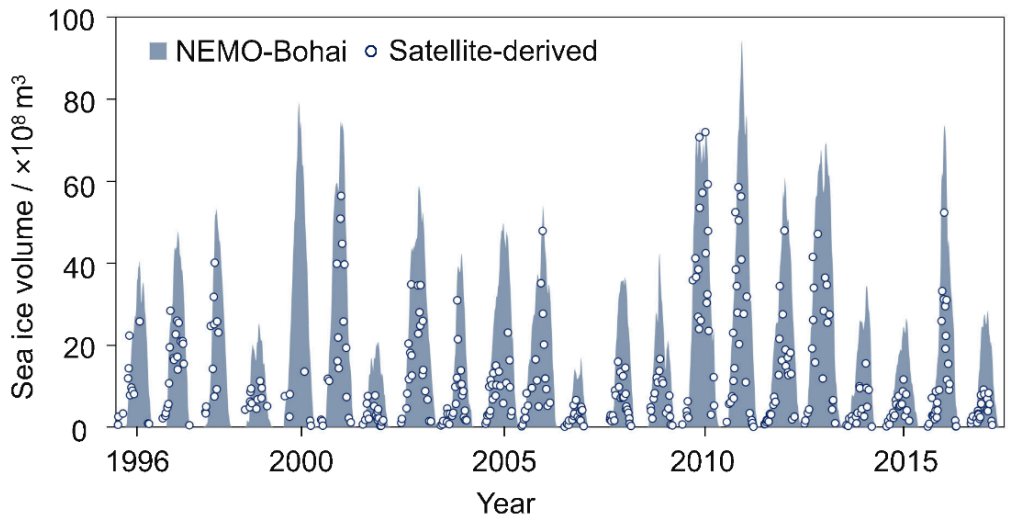

Figure 8: Comparison of daily sea ice volume between satellite-derived data (circles) and NEMO-Bohai simulations (grey bars) from 1996 to 2017. 
Results of model comparison with in situ data and satellite derived data confirm the robustness of the developed model, which allows us to use it in a more detailed evaluation of the spatial and temporal changes of Bohai Sea ice and study the continuous processes of freezing and melting at daily scales.

\section{Initial results and applications}

\subsection{Ocean}

\subsubsection{Sea surface temperature}

Fig. 9 shows the seasonal changes of monthly average SST in Bohai Sea. There is an obvious 'warm tongue' starting from the Bohai Strait to the central Bohai Sea in winter (December, January and February) due to the warm current from the Yellow Sea, which turns into a 'cold tongue' in summer due to faster temperature increases in coastal shallow waters as also the influence of the warm current from the Yellow Sea weakens. During January and February, the SST is below $0{ }^{\circ} \mathrm{C}$ in all three bays. There are large areas with SSTs below $-1{ }^{\circ} \mathrm{C}$ in Liaodong Bay, which is the coldest sea in China during the winter (Ju and Xiong, 2013). This extremely cold water provides ideal platform for sea ice formation.
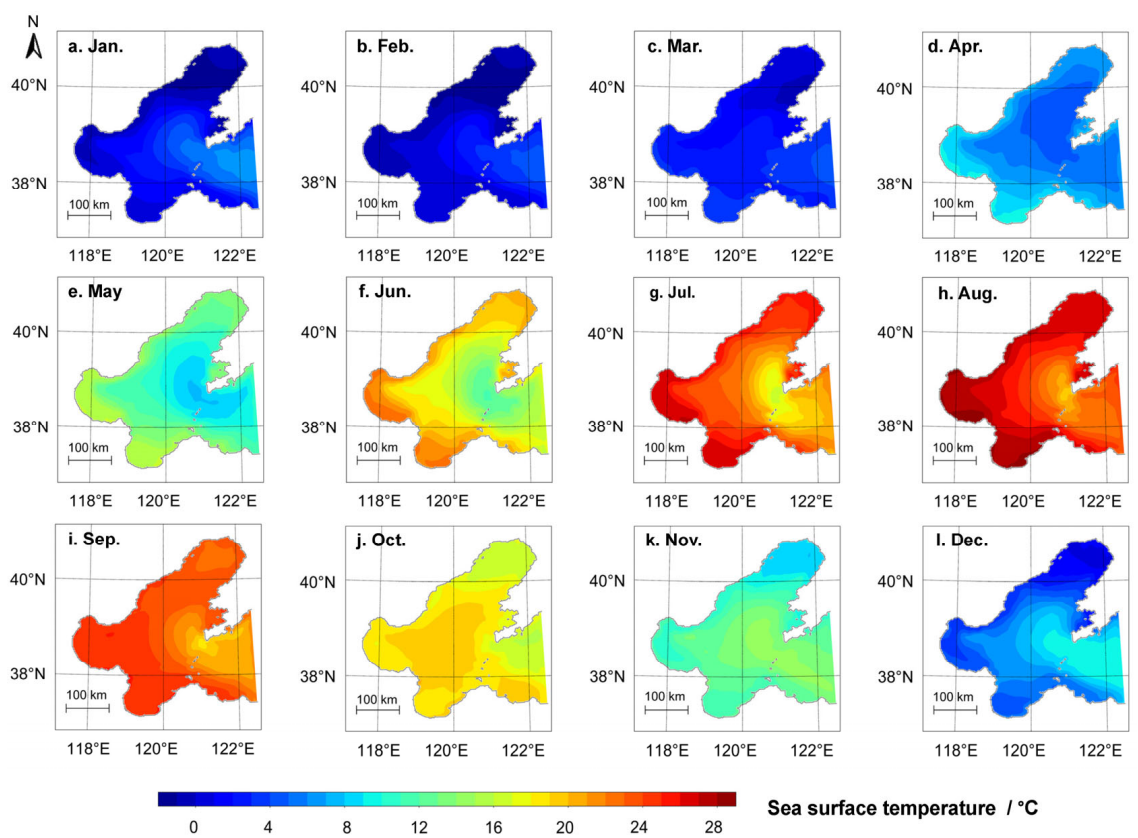

Figure 9: Spatial distributions of multi-year monthly average sea surface temperature in the Bohai Sea for 


\subsubsection{Sea surface salinity}

As shown in Fig. 10, except for estuaries, the salinity isolines of the Bohai Sea are roughly parallel to the coast as the salinity in the coastal water is generally low due to river runoff. The average salinity of the whole Bohai Sea is low in summer (lowest in August at $29.5 \mathrm{~g} \mathrm{~kg}^{-1}$ ) and high in winter (highest in exhibits the highest salinity in the entire Bohai Sea, with an average of about $32.8 \mathrm{~g} \mathrm{~kg}^{-1}$.
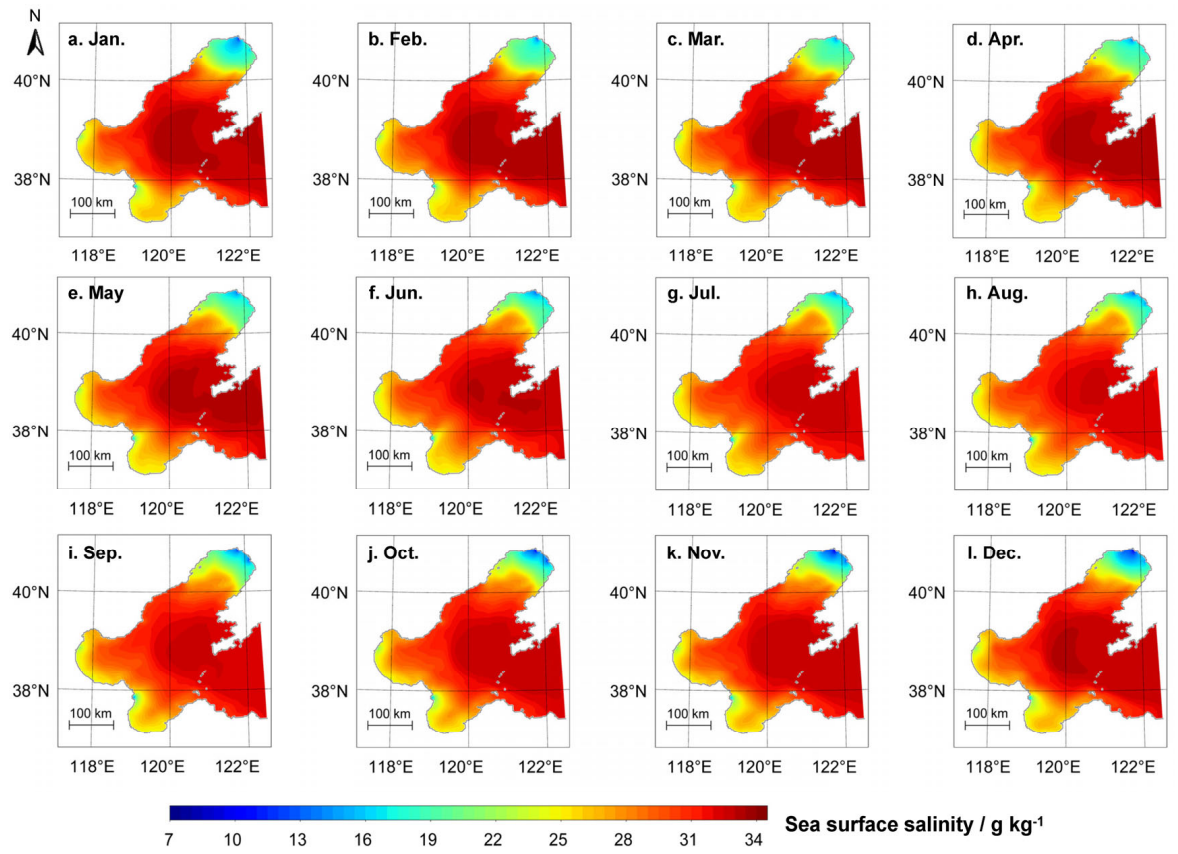

16

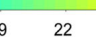

Figure 10: Spatial distributions of multi-year monthly average sea surface salinity in the Bohai Sea during 1996-2017.

\subsection{Sea ice}

\subsubsection{Temporal variation of Bohai sea ice}

The variation of annual average and maximum sea ice area in the Bohai Sea based on NEMO-Bohai from 1996 to 2017 are shown in Fig. 11a and Fig. 11b, respectively. Annual average sea ice area (AASIA) is averaged by the DSIAs during the ice period for each year. The sea ice area exhibits obvious interannual and decadal variability in the study period. The mean AASIA during the period $1996-2017$ is $1.07 \times 10^{4}$ $\mathrm{km}^{2}$, accounting for $14.3 \%$ of the total sea area. The $2010 / 11$ and $2011 / 12$ winters exhibited high AASIA 
values of $1.71 \times 10^{4} \mathrm{~km}^{2}$ and $1.73 \times 10^{4} \mathrm{~km}^{2}$, which cover $22.8 \%$ and $23.1 \%$, respectively. The minimum AASIA reaches $0.54 \times 10^{4} \mathrm{~km}^{2}(7.2 \%$ coverage $)$ in 2007 winter, only accounting for half of the multi-year average AASIA. Analogously to AASIA, AMSIA is the maximum of the DSIAs during the period for each year. The mean AMSIA during $1996-2017$ is $2.07 \times 10^{4} \mathrm{~km}^{2}(27.6 \%$ coverage), and the AMSIA values in 2001/02, 2010/11, 2011/12 and 2016/17 winters are particularly high, larger than $3.00 \times 10^{4} \mathrm{~km}^{2}$ ( $40 \%$ coverage). No significant trend in AASIA was observed, while AMSIA showed a non-significant increasing trend with $0.1 \times 10^{4} \mathrm{~km}^{2} \operatorname{decade}^{-1}(r=0.08, p=0.72)$ from 1996 to 2017 . In addition, a strong positive correlation between AASIA and AMSIA $(r=0.94, p<0.01)$ was found.
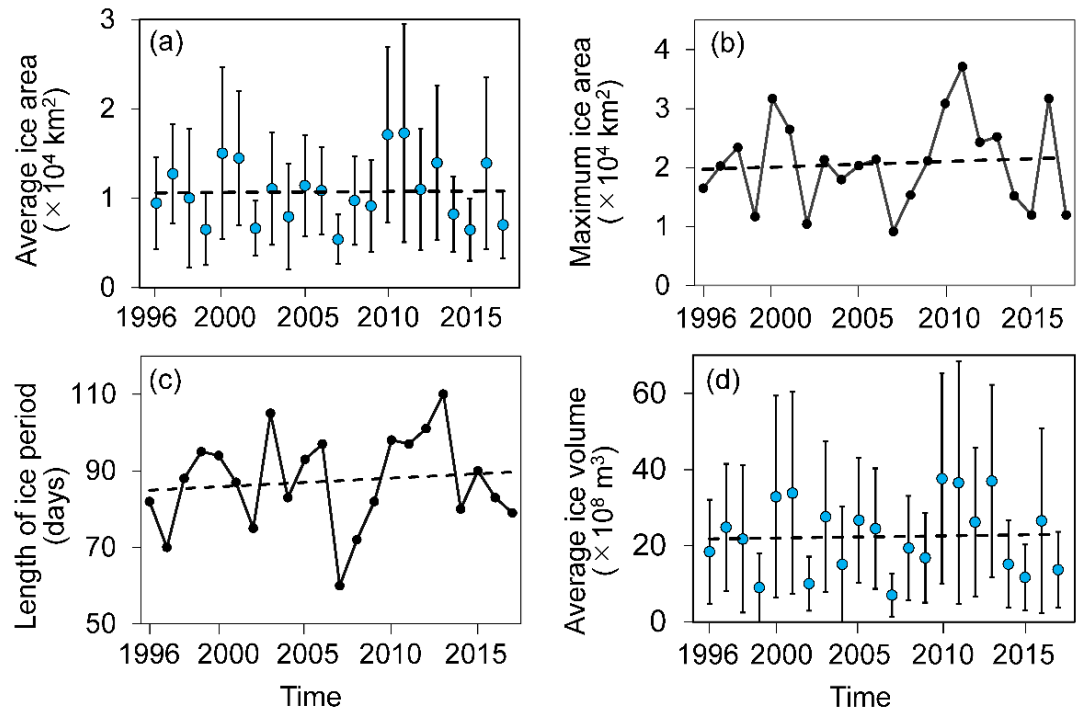

Figure 11: The annual average sea ice area (a), the annual maximum sea ice area (b), the simulated length of ice period (c), and the annual average sea ice volume (d) in the Bohai Sea from 1996 to 2017. The blue dots present the annual average values and the error bars stand for one standard deviation, and the dotted lines represent 22 a-trends obtained through linear fitting.

The length of the ice period is defined as days with sea ice area greater than $100 \mathrm{~km}^{2}$ from December to March. It varies from 60 to 110 days during the period 1996-2017 as shown in Fig. 11c. The mean of the length of ice period is 87 days, with the standard deviation of 12 days, and there is a slight increasing but statistically insignificant trend $(r=0.12, p=0.59)$. The annual average sea ice volume (AASIV, defined as the average of daily sea ice volume in the ice period for each year) from 1996 to 2017 is 2.24 billion $\mathrm{m}^{3}$. As shown in Fig. 11d, no significant trends can be found for AASIV during the study period. The highest value of AASIV appeared in 2010, which was 3.76 billion $\mathrm{m}^{3}$, and the lowest value appeared in 
2007 with 0.7 billion $\mathrm{m}^{3}$, accounting for only $18.6 \%$ of the ice volume of the highest year. The strong interannual variability of sea ice volume is determined by the strong interannual variability of sea ice area $(r=0.96, p<0.01)$. Interestingly, it can be noticed that ice period is not highly correlated with sea ice area or thickness, implying complicated processes of sea ice forming, growth and thaw in Bohai Sea.

The climatological seasonal cycles of the sea ice area and volume in the Bohai Sea averaged over 1996-2017 both show unimodal variations (Fig. 12). Ice usually starts to form in mid-December and reaches the maximum in early February. Then it starts to melt until the Bohai Sea becomes totally ice free by mid-to-late March. The climatological mean of the length of ice period is about three and a half months, and the freezing period ( $\sim 8$ weeks) is longer than the thawing period ( $\sim 7$ weeks). The asymmetrical process is related to changing rates of air temperature in freezing and thawing periods (Yan et al., 2020). Similarly, the seasonal variation of sea ice volume is an asymmetrical process. It is worth mentioning that the standard deviations of sea ice area and volume during the freezing period are quite large, showing that the Bohai Sea ice has a large inter-annual variability.
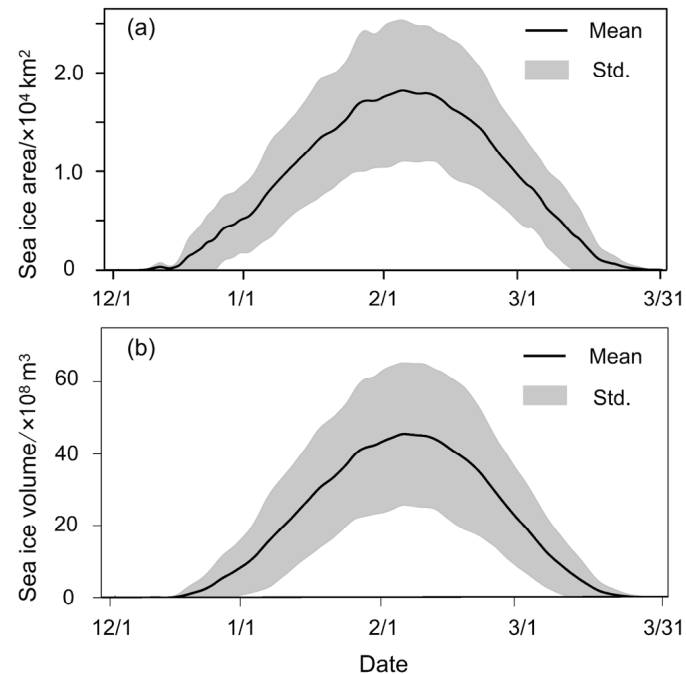

Figure 12: Seasonal cycles of daily sea ice area (a) and sea ice volume (b) in the Bohai Sea. The lines show the daily averages and the shading denotes one standard deviation. The seasonal cycles are calculated for the periods 1996-2017.

\subsubsection{Spatial variation of Bohai sea ice}


Liaodong Bay, next in Bohai Bay, followed by Laizhou Bay, showing significant variation with latitude. On the contrary, the melting process happens exactly at the reverse order. Similar to the aforementioned temporal changes in last section, the sea ice concentration reaches the peak in February. Seawater in Liaodong Bay freezes most severely and the high concentration zone moves from the north in January to the east in February where it survives the longest until March.
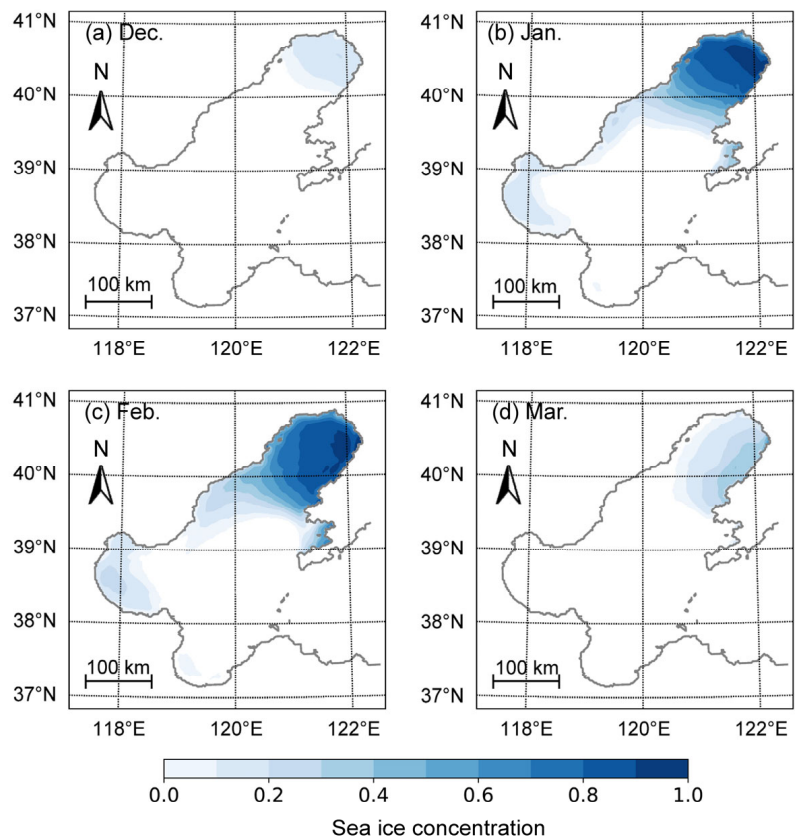

Figure 13: Climatological monthly mean sea ice concentration in the Bohai Sea during 1996-2017, which is calculated as the average of all daily sea ice concentrations for each month during the ice period.

As shown from Fig. 14, sea ice thickness shows quite similar seasonal and spatial features with sea ice concentration. The monthly mean Bohai Sea ice thickness simulated by NEMO-Bohai usually reaches its maximum in February, with a monthly mean thickness of $16.9 \mathrm{~cm}$, following the second highest monthly mean thickness of $15.8 \mathrm{~cm}$ in January. Sea ice is thicker in the east coast of Liaodong Bay than that in the west coast in January and February. The maximum sea ice thickness appears near the Bayuquan on the east coast of Liaodong Bay, where the thickness reaches up to $\sim 60.0 \mathrm{~cm}$ in February. 

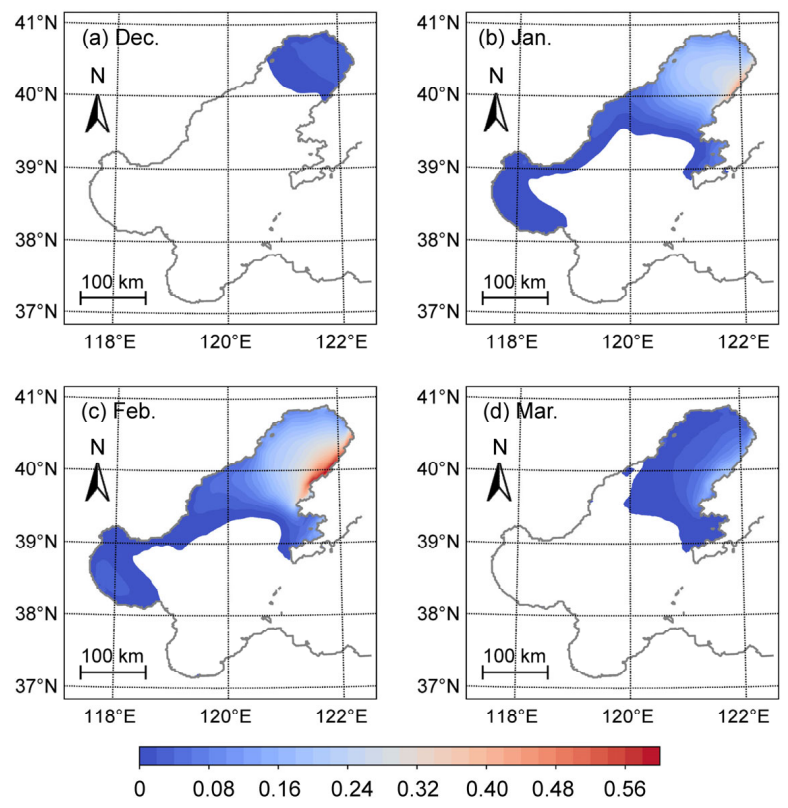

Sea ice thickness / $\mathrm{m}$

Figure 14: Similar to figure 13 but for sea ice thickness.

According to the guideline for risk assessment and zoning of sea ice disaster issued by the State Oceanic Administration in 2016, a high-risk level is reached when sea ice thickness becomes greater than

$44525 \mathrm{~cm}$, while the risk level is low when sea ice thickness is lower than $10 \mathrm{~cm}$. When sea ice thickness is between $10 \mathrm{~cm}$ and $25 \mathrm{~cm}$, the risk level is moderate. Accordingly, in this study, the thresholds for moderate risk and high-risk level of sea ice disaster are set at $10 \mathrm{~cm}$ and $25 \mathrm{~cm}$, respectively. In Fig. 15, sea ice risk maps are calculated based on daily sea ice thickness from 1996 to 2017 and they clearly show that the high-risk area is mainly located at Liaodong Bay, with the highest risk area in the eastern disasters. 

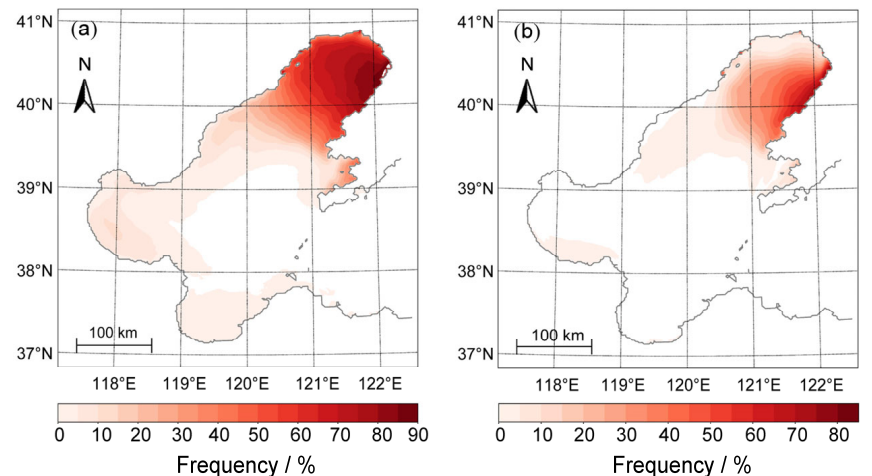

Figure 15: Frequency distribution of daily sea ice thickness larger than $10 \mathrm{~cm}$ (a) and $25 \mathrm{~cm}$ (b) in the Bohai Sea during 1996-2017.

As the drift ice is a major component in Bohai Sea ice, studying its motion characteristics is also quite important. As shown in Fig. 16, the direction is mainly northeast-southwesterly, and the drift exhibits a high spatial variability. The zone with the highest sea ice velocity $\left(\sim 0.15 \mathrm{~m} \mathrm{~s}^{-1}\right.$ and mainly directed to south-west) is visible at the southeast edge of Liaodong Bay, and is next to the high concentration and thickness area. In February, the velocity in the northern Liaodong Bay is significantly lower than that in the southern part near the ice edge.
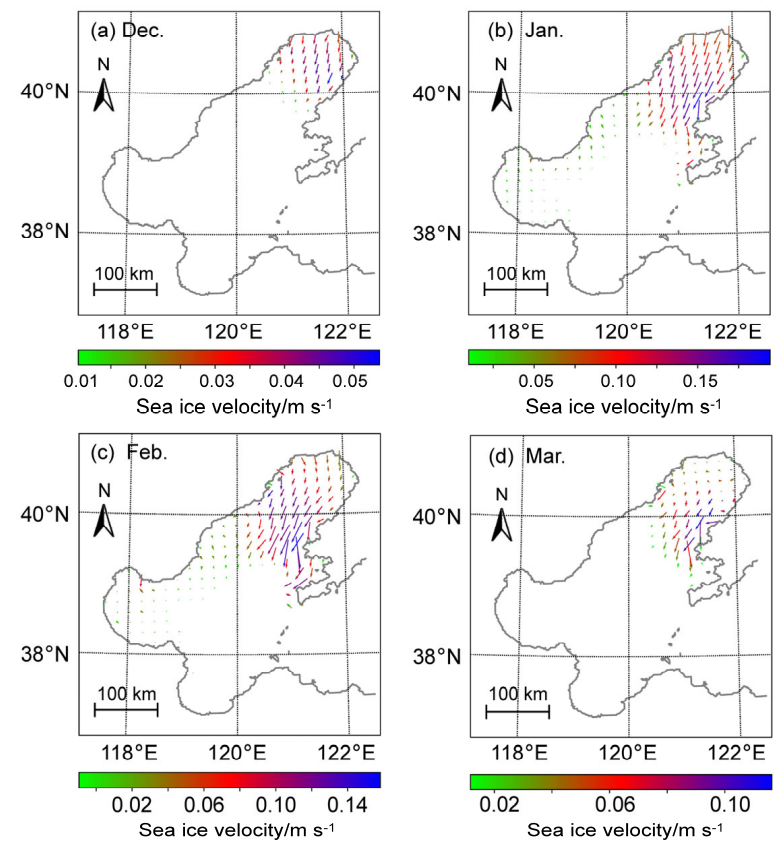

Figure 16: Similar to figure 13 but for sea ice velocity. 


\section{Conclusion and perspectives for the modelling platform}

In this study we provided a detailed description of NEMO-Bohai, a newly developed set-up of an ocean-ice model for the Bohai Sea. Primary intent of our study was to test how NEMO-Bohai represents the ocean characteristics mainly in terms of sea ice properties.

Comparisons with observational data confirm that NEMO-Bohai is able to reproduce reasonably well the ocean surface information, including SSH, SST, and SSS. However, the ongoing development of NEMO ocean engine soon providing an updated version with the inclusion of wetting and drying processes, could improve the model performance in terms of sea surface height in shallow areas (Hordoir et al., 2019), especially for the Bohai Sea with average depth of only $18 \mathrm{~m}$. In addition, a higher-precision bathymetry could possibly improve the SSH performance. In this study, the monthly climatology of coastal runoff flux from Dai et al. (2009) recorded only for 1948-2004, which is different from the study period. Moreover, we assume that the river salinity is set to $0 \mathrm{~g} \cdot \mathrm{kg}^{-1}$ and the runoff temperature is same as the ocean surface. A major future development would be the use of gauge records with observations of salinity and temperature assimilated into the NEMO-Bohai model, which would reduce uncertainties in temperature and salinity. Furthermore, a possible implementation of multiple embedded method (Hvatov et al., 2019; Schwarzkopf et al., 2019) such as Global Ocean-West Pacific Ocean-East China Sea-Bohai Sea rather than current Global Ocean-Bohai Sea direct nesting, should be investigated in the future. Moreover, interactive feedback from Bohai Sea to global Ocean could also be considered in a two-way coupling method compared to current one-way nesting.

For the sea ice component, NEMO-Bohai reproduced satisfactorily the seasonal and interannual variabilities of ice area compared to the satellite remote sensing data for the period 1996-2017. The modeled dates of annual maximum sea ice area were on average 0.9 days earlier than the observed ones. compared to the satellite data. Therefore, NEMO-Bohai can reliably be used to provide ice information during the dates without satellite-derived data. Nevertheless, it is worth mentioning that the simulated sea ice area tends to be a somewhat overestimated, which is also reported for other seas in earlier NEMOrelated publications (Blockley et al., 2014; Massonnet et al., 2011; Rjazin et al., 2019). NEMO-Bohai 
albedo may cause slow melting process, which is not taking realistically into account the relevant physical processes, such as surface melt ponds, as the surface albedo continues to decrease until sea ice is completely disappeared (Mortin et al., 2016). It is also possible related to the model unrealism of solar radiation penetration into ice, which strongly affects the surface energy balance (Light et al., 2008), thus regional atmospheric forcing data with higher accuracy and resolution can be used for further development. In addition, the space discrepancy between modeled sea ice thickness and extremely limited in situ observations makes their comparison difficult and introduces significant uncertainties.

In conclusion, NEMO-Bohai is able to simulate ocean and sea ice properties with good skill in a broad spatiotemporal context, especially in terms of seasonal evolution and long-term interannual variations of sea ice. This finding implies that NEMO-Bohai well complements the discontinuous satellite data in sea ice hazard risk analysis. Therefore, NEMO-Bohai is a useful tool, not only for longterm ocean and ice simulations, but also for the ocean and climate change studies.

\section{Code and data availability}

505 The NEMO-Bohai is built upon the standard NEMO code (nemo 4.0 beta, revision 10226). The reference code is available at the NEMO website (http://www.nemo-ocean.eu/) through the following link: http://forge.ipsl.jussieu.fr/nemo/svn/NEMO/trunk (last access: 20 May 2021). The parameters and configuration files running the NEMO-Bohai, such as namelists, bathymetry, boundary coordinates and definition files, forcing data etc., together with the scripts to run the model, are available at https://doi.org/10.5281/zenodo.4892454. The forcing data for the year 2010 are included in the Zenodo archive.

\section{Author contributions}

YY, WG and PU designed the study. YY and AG ran the experiments. YY and YX analyzed the model and observational data. YY and PU wrote the manuscript. All authors provided scientific input.

\section{Competing interests}

The authors declare that they have no conflict of interest. 


\section{Acknowledgements}

This study was financially supported by the National Natural Science Foundation of China (Nos. 41977406, 41571510), the Academy of Finland (grant 322432), the China Scholarship Council (No.

2017YFA0604903). This work was granted access to the HPC resources of CSC - IT Center for Science.

We gratefully thank Juha Lento, Robinson Hordoir, Yongmei Gong and Yu Zhang for sharing the scripts for input data processing.

\section{References}

525 Aksenov, Y., Blockley, E., Chevallier, M., Feltham, D., Fichefet, T., Garric, G., Holland, P., Iovino, D., Madec, G., Massonnet, F., Ridley, J., Rousset, C., Salas, D., Schroeder, D., Tietsche, S., and Vancoppenolle, M.: Sea Ice modelling Integrated Initiative $\left(\mathrm{SI}^{3}\right)$ - The NEMO sea ice engine, Scientific Notes of Climate Modelling Center, ISSN 1288-1619, Institut Pierre-Simon Laplace (IPSL), doi:10.5281/zenodo.1471689, 2019.

Bai, S. and Wu, H.: Numerical sea ice forecast for the Bohai Sea, Acta Meteorologica Sinica (in Chinese), 56, 139-153, 1998.

Bai, X., Wang, J., Liu, Q., Wang, D., and Liu, Y.: Severe ice conditions in the Bohai Sea, China, and mild ice conditions in the great lakes during the 2009/10 winter: Links to El Nino and a strong negative arctic oscillation, J Appl Meteorol Clim, 50, 1922-1935, 2011.

Blanke, B. and Delecluse, P.: Variability of the tropical Atlantic Ocean simulated by a general circulation model with two different mixed-layer physics, Journal of Physical Oceanography, 23, 1363-1388, 1993.

Blockley, E. W., Martin, M. J., McLaren, A. J., Ryan, A. G., Waters, J., Lea, D. J., Mirouze, I., Peterson, K. A., Sellar, A., and Storkey, D.: Recent development of the Met Office operational ocean forecasting system: an overview and assessment of the new Global FOAM forecasts, Geoscientific Model Development, 7, 2613-2638, 2014.

Bouillon, S., Fichefet, T., Legat, V., and Madec, G.: The elastic-viscous-plastic method revisited, Ocean Modelling, 71, 2-12, 2013.

Courtois, P., Hu, X., Pennelly, C., Spence, P., and Myers, P. G.: Mixed layer depth calculation in deep convection regions in ocean numerical models, Ocean Modelling, 120, 60-78, 2017.

Dai, A., Qian, T., Trenberth, K., and Milliman, J.: Changes in continental freshwater discharge from 1948 to 2004, J Climate, 22, 2773-2792, 2009.

Declerck, A., Ourmières, Y., and Molcard, A.: Assessment of the coastal dynamics in a nested zoom and feedback on the boundary current: the North-Western Mediterranean Sea case, Ocean Dynamics, 66, 1529-1542, 2016.

Depoorter, M. A., Bamber, J. L., Griggs, J. A., Lenaerts, J. T., Ligtenberg, S. R., van den Broeke, M. R., and Moholdt, G.: Calving fluxes and basal melt rates of Antarctic ice shelves, Nature, 502, 89-92, 2013.

Drouard, M. and Cassou, C.: A modeling-and process-oriented study to investigate the projected change 
of ENSO-forced wintertime teleconnectivity in a warmer world, J Climate, 32, 8047-8068, 2019.

Egbert, G. D. and Erofeeva, S. Y.: Efficient inverse modeling of barotropic ocean tides, Journal of Atmospheric and Oceanic Technology, 19, 183-204, 2002.

Engedahl, H.: Use of the flow relaxation scheme in a three-dimensional baroclinic ocean model with realistic topography, Tellus A, 47, 365-382, 1995.

Feucher, C., Garcia-Quintana, Y., Yashayaev, I., Hu, X., and Myers, P. G.: Labrador sea water formation rate and its impact on the local meridional overturning circulation, Journal of Geophysical Research: Oceans, 124, 5654-5670, 2019.

Flather, R. A.: A tidal model of the north-west European continental shelf, Memoires Societe Royale des Sciences de Liege, 10, 141-164, 1976.

Fu, M., Liu, H., Jin, X., and He, K.: National-to port-level inventories of shipping emissions in China, Environ Res Lett, 12, 114024, 2017.

Gong, D., Kim, S., and Ho, C.: Arctic oscillation and ice severity in the Bohai Sea, East Asia, Int J Climatol, 27, 1287-1302, 2007.

Graham, J. A., O'Dea, E., Holt, J., Polton, J., Hewitt, H. T., Furner, R., Guihou, K., Brereton, A., Arnold, A., and Wakelin, S.: AMM15: a new high-resolution NEMO configuration for operational simulation of the European north-west shelf, Geoscientific Model Development, 11, 681-696, 2018.

Gu, W., Liu, C., Yuan, S., Li, N., Chao, J., Li, L., and Xu, Y.: Spatial distribution characteristics of seaice-hazard risk in Bohai, China, Ann Glaciol, 54, 73-79, 2013.

Gu, W., Shi, P., Chen, W., Xie, F., Xu, Y., and Yuan, S.: Sea ice reserves estimates and quality evaluation, Science Press, Beijing, 2014.

Gunduz, M., Özsoy, E., and Hordoir, R.: A model of Black Sea circulation with strait exchange (20082018), Geoscientific Model Development, 13, 121-138, 2020.

Harada, Y., Kamahori, H., Kobayashi, C., Endo, H., Kobayashi, S., Ota, Y., Onoda, H., Onogi, K., Miyaoka, K., and Takahashi, K.: The JRA-55 reanalysis: Representation of atmospheric circulation and climate variability, Journal of the Meteorological Society of Japan. Ser. II, 94, 269-302, 2016.

Hordoir, R., Axell, L., Höglund, A., Dieterich, C., Fransner, F., Gröger, M., Liu, Y., Pemberton, P., Schimanke, S., Andersson, H., Ljungemyr, P., Nygren, P., Falahat, S., Nord, A., Jönsson, A., Lake, I., Döös, K., Hieronymus, M., Dietze, H., Löptien, U., Kuznetsov, I., Westerlund, A., Tuomi, L., and Haapala, J.: Nemo-Nordic 1.0: a NEMO-based ocean model for the Baltic and North seas - research and operational applications, Geosci. Model Dev., 12, 363-386, 2019.

Hvatov, A., Nikitin, N. O., Kalyuzhnaya, A. V., and Kosukhin, S. S.: Adaptation of NEMO-LIM3 model for multigrid high resolution Arctic simulation, Ocean Modelling, 141, 101427, 2019.

$\mathrm{Ju}, \mathrm{X}$. and Xiong, X.: Distributions and seasonal changes of water temperature in the Bohai Sea,Yellow Sea and East China Sea, Advances in Marine Science (in Chinese), 31, 55-68, 2013.

590 Karvonen, J., Shi, L., Cheng, B., Simila, M., Makynen, M., and Vihma, T.: Bohai sea ice parameter estimation based on thermodynamic ice model and earth observation data, Remote Sens-Basel, 9, $234,2017$.

Kimmritz, M., Losch, M., and Danilov, S.: A comparison of viscous-plastic sea ice solvers with and without replacement pressure, Ocean Modelling, 115, 59-69, 2017.

595 Kobayashi, S., Ota, Y., Harada, Y., Ebita, A., Moriya, M., Onoda, H., Onogi, K., Kamahori, H., Kobayashi, C., Endo, H., Miyaoka, K., and Takahashi, K.: The JRA-55 reanalysis: General specifications and basic characteristics, Journal of the Meteorological Society of Japan. Ser. II, 93, 5-48, 2015.

Large, W. G. and Yeager, S. G.: The global climatology of an interannually varying air-sea flux data set, 
Leppäranta, M.: The drift of sea ice, Springer Science \& Business Media, 2011.

Li, Z., Lu, P., and Sodhi, D. S.: Ice engineering sub-areas in Bohai from ice physical and mechanical parameters, Advances in Water Science (in Chinese), 15, 598-602, 2004.

Li, Z., Zhang, L., Lu, P., Leppäranta, M., and Li, G.: Experimental study on the effect of porosity on the uniaxial compressive strength of sea ice in Bohai Sea, Science China Technological Sciences, 54, 2429-2436, 2011.

Light, B., Grenfell, T. C., and Perovich, D. K.: Transmission and absorption of solar radiation by Arctic sea ice during the melt season, Journal of Geophysical Research: Oceans, 113, C03023, 2008.

Liu, C., Gu, W., Chao, J., Li, L., Yuan, S., and Xu, Y.: Spatio-temporal characteristics of the sea-ice volume of the Bohai Sea, China, in winter 2009/10, Ann Glaciol, 54, 97-104, 2013.

Liu, Q., Liu, Y., Bai, S., Zhang, Q., Li, B., and Li, C.: Numerical sea ice forecast for the Bohai Sea in the winter of 2002-2003, Marine Forecasts (in Chinese), 20, 60-67, 2003.

Locarnini, R. A., Mishonov, A. V., Antonov, J. I., Boyer, T. P., Garcia, H. E., Baranova, O. K., Zweng, M. M., Paver, C. R., Reagan, J. R., Johnson, D. R., Hamilton, M., and Seidov, D.: World ocean atlas 2013, volume 1: Temperature, NOAA Atlas NESDIS 73, 40 pp., 2013.

Madec, G., and the NEMO team: NEMO ocean engine. Note du Pôle de modélisation, Institut PierreSimon Laplace No 27, France, ISSN No No 1288-1619, 2016.

Massonnet, F., Barthélemy, A., Worou, K., Fichefet, T., Vancoppenolle, M., Rousset, C., and MorenoChamarro, E.: On the discretization of the ice thickness distribution in the NEMO3. 6-LIM3 global ocean-sea ice model, Geoscientific Model Development, 12, 3745-3758, 2019.

Massonnet, F., Fichefet, T., Goosse, H., Vancoppenolle, M., Mathiot, P., and König Beatty, C.: On the influence of model physics on simulations of Arctic and Antarctic sea ice, The Cryosphere, 5, 687699, 2011.

Mortin, J., Svensson, G., Graversen, R. G., Kapsch, M.-L., Stroeve, J. C., and Boisvert, L. N.: Melt onset over Arctic sea ice controlled by atmospheric moisture transport, Geophysical Research Letters, 43, 6636-6642, 2016.

O'Dea, E., Furner, R., Wakelin, S., Siddorn, J., While, J., Sykes, P., King, R., Holt, J., and Hewitt, H.: The CO5 configuration of the $7 \mathrm{~km}$ Atlantic Margin Model: large-scale biases and sensitivity to forcing, physics options and vertical resolution, Geoscientific Model Development, 10, 2947, 2017.

Obermann-Hellhund, A., Conte, D., Somot, S., Torma, C. Z., and Ahrens, B.: Mistral and Tramontane wind systems in climate simulations from 1950 to 2100, Climate dynamics, 50, 693-703, 2018.

Pemberton, P., Löptien, U., Hordoir, R., Höglund, A., Schimanke, S., Axell, L., and Haapala, J.: Sea-ice evaluation of NEMO-Nordic 1.0: a NEMO-LIM3.6-based ocean-sea-ice model setup for the North Sea and Baltic Sea, Geoscientific Model Development, 10, 3105-3123, 2017.

Rjazin, J., Hordoir, R., and Parn, O.: Evaluation of the NEMO-Nordic model by comparing the sea-ice concentration values in the Baltic Sea, Journal of Ocean Technology, 14, 183, 2019.

Schwarzkopf, F. U., Biastoch, A., Böning, C. W., Chanut, J., Durgadoo, J. V., Getzlaff, K., Harlaß, J., Rieck, J. K., Roth, C., Scheinert, M. M., and Schubert, R.: The INALT family - a set of highresolution nests for the Agulhas Current system within global NEMO ocean/sea-ice configurations, Geoscientific Model Development, 12, 3329-3355, 2019.

Shi, W. and Wang, M.: Sea ice properties in the Bohai Sea measured by MODIS-Aqua: 2. Study of sea ice seasonal and interannual variability, Journal of Marine Systems, 95, 41-49, 2012.

$\mathrm{Su}, \mathrm{H} ., \mathrm{Ji}, \mathrm{B}$., and Wang, Y.: Sea ice extent detection in the Bohai Sea using Sentinel-3 OLCI data, Remote 
Sens-Basel, 11, 2436, 2019.

$\mathrm{Su}, \mathrm{H}$. and Wang, Y.: Using MODIS data to estimate sea ice thickness in the Bohai Sea (China) in the 2009-2010 winter, J Geophys Res-Oceans, 117, C10018, 2012.

Su, J., Wu, H., Zhang, Y., Liu, Q., and Bai, S.: A coupled ice-ocean model for the Bohai Sea: I. Study on model and parameter, Acta Oceanol Sin, 23, 597-608, 2004.

Tang, M., Liu, Q., Liu, Y., and Bai, S.: The numerical simulation of sea ice in the Bohai Sea, Marine Forecasts (in Chinese), 27, 48-52, 2010.

Tedesco, L., Miettunen, E., An, B. W., Haapala, J., Kaartokallio, H., and Miller, L. A.: Long-term mesoscale variability of modelled sea-ice primary production in the northern Baltic Sea, Elementa: Science of the Anthropocene, 5, 29, 2017.

Thompson, B., Sanchez, C., Sun, X., Song, G., Liu, J., Huang, X., and Tkalich, P.: A high-resolution atmosphere-ocean coupled model for the western Maritime Continent: development and preliminary assessment, Climate Dynamics, 52, 3951-3981, 2019.

Uotila, P., Iovino, D., Vancoppenolle, M., Lensu, M., and Rousset, C.: Comparing sea ice, hydrography and circulation between NEMO3.6 LIM3 and LIM2, Geosci. Model Dev., 10, 1009-1031, 2017.

Voldoire, A., Sanchez-Gomez, E., y Mélia, D. S., Decharme, B., Cassou, C., Sénési, S., Valcke, S., Beau, I., Alias, A., and Chevallier, M.: The CNRM-CM5. 1 global climate model: description and basic evaluation, Climate dynamics, 40, 2091-2121, 2013.

Wang, R., Liu, X., and Zhang, L.: Numerical tests of sea ice, Acta Oceanologica Sinica (in Chinese), 6, 572-582, 1984.

Westerlund, A.: A Gulf of Finland (GoF) configuration for the NEMO ocean model, available at: https://github.com/fmidev/nemo-gof/, last access: 15 December 2019. 2019.

$\mathrm{Wu}, \mathrm{H} .:$ Mathematical representations of sea ice dynamic-thermodynamic processes, Oceanologia et Limnologia Sinica (in Chinese), 22, 221-228, 1991.

Wu, H., Bai, S., Zhang, Z., and Li, G.: Numerical simulation for dynamical processes of sea ice, Acta Oceanol Sin, 16, 303-325, 1997.

Yan, H., Wang, N., Wu, N., and Lin, W.: Abundance, habitat conditions, and conservation of the largha seal (Phoca largha) during the past half century in the Bohai Sea, China, Mammal Study, 43, 1-10, 2018.

Yan, Y., Gu, W., Xu, Y., and Li, Q.: The in situ observation of modelled sea ice drift characteristics in the Bohai Sea, Acta Oceanol Sin, 38, 17-25, 2019.

Yan, Y., Shao, D., Gu, W., Liu, C., Li, Q., Chao, J., Tao, J., and Xu, Y.: Multidecadal anomalies of Bohai Sea ice cover and potential climate driving factors during 1988-2015, Environ Res Lett, 12, 094014 , 2017.

Yan, Y., Uotila, P., Huang, K., and Gu, W.: Variability of sea ice area in the Bohai Sea from 1958 to 2015, Science of The Total Environment, 709, 136164, 2020.

Yang, L., Xu, X., Zhang, P., Han, J., Li, B., and Berggren, P.: Classification of underwater vocalizations of wild spotted seals (Phoca largha) in Liaodong Bay, China, The Journal of the Acoustical Society of America, 141, 2256-2262, 2017.

Yuan, B., Huang, R., Jiao, Y., Guo, D., Shang, J., and Zhang, H.: Analysis of sea surface temperature and salinity based on the observed buoys data in the Bohai Sea, Marine Forecasts (in Chinese), 32, 44 $50,2015$.

Yuan, S., Gu, W., Xu, Y., Wang, P., Huang, S., Le, Z., and Cong, J.: The estimate of sea ice resources quantity in the Bohai Sea based on NOAA/AVHRR data, Acta Oceanol Sin, 31, 33-40, 2012. 
https://doi.org/10.5194/gmd-2021-100

Preprint. Discussion started: 16 June 2021

(c) Author(s) 2021. CC BY 4.0 License.

Zalesak, S. T.: Fully multidimensional flux-corrected transport algorithms for fluids, Journal of Computational Physics, 31, 335-362, 1979.

Zeng, T., Shi, L., Marko, M., Cheng, B., Zou, J., and Zhang, Z.: Sea ice thickness analyses for the Bohai Sea using MODIS thermal infrared imagery, Acta Oceanol Sin, 35, 96-104, 2016.

Zhang, Q. and Zhang, N.: A three-dimensional numerical model of sea ice evolution in the Bohai Sea, Journal of Tianjin University (Science and Technology), 46, 333-341, 2013.

Zhang, X., Zhang, Z., Xu, Z., Li, G., Sun, Q., and Hou, X.: Sea ice disasters and their impacts since 2000 in Laizhou Bay of Bohai Sea, China, Nat Hazards, 65, 27-40, 2013.

Zheng, J., Ke, C., and Shao, Z.: Winter sea ice albedo variations in the Bohai Sea of China, Acta Oceanol Sin, 36, 56-63, 2017.

Zweng, M. M., Reagan, J. R., Antonov, J. I., Locarnini, R. A., Mishonov, A. V., Boyer, T. P., Garcia, H. E., Baranova, O. K., Johnson, D. R., and Seidov, D.: World ocean atlas 2013, volume 2: Salinity, NOAA Atlas NESDIS 74, 39 pp., 2013. 